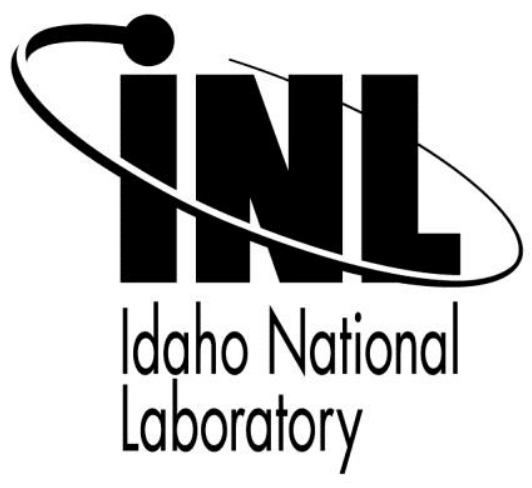

\title{
An Equation of State and Compendium of Thermophysical Properties of Liquid Tin, a Prospective Plasma-facing Material
}

\section{Symposium on Fusion Engineering}

\author{
Paul W. Humrickhouse \\ (Idaho National Laboratory)
}

\author{
July 2017
}

This is an accepted manuscript of a paper intended for publication in a journal. This document was prepared as an account of work sponsored by an agency of the United States Government. Neither the United States Government nor any agency thereof, or any of their employees, makes any warranty, expressed or implied, or assumes any legal liability or responsibility for any third party's use, or the results of such use, of any information, apparatus, product or process disclosed in this report, or represents that its use by such third party would not infringe privately owned rights. The views expressed in this paper are not necessarily those of the United States Government or the sponsoring agency.

Prepared for the U.S. Department of Energy Office of Nuclear Energy

Under DOE Idaho Operations Office Contract DE-AC07-05ID14517 



\title{
An Equation of State and Compendium of Thermophysical Properties of Liquid Tin, a Prospective Plasma-Facing Material
}

\author{
Paul W. Humrickhouse, Member, IEEE
}

\begin{abstract}
In this work we collect and summarize a variety of thermophysical properties of liquid tin, which is a prospective plasma-facing material in fusion reactors. These include the thermodynamic properties density, specific heat, sound speed, and vapor pressure; transport properties such as thermal conductivity, viscosity, and surface tension; and hydrogen isotope solubility and diffusivity. The thermodynamic property data are used to fit an equation of state that accurately describes these, and which has been implemented in MELCOR for fusion in order to model systems featuring liquid tin PFCs and coolant loops. Few data on hydrogen solubility could be found, and these differ by some orders of magnitude; diffusivity appears not to have been measured precisely and for subsequent analyses theoretical estimates will have to be relied upon.
\end{abstract}

Index Terms-Plasma facing components, Liquid tin, Equation of state, thermophysical properties

\section{INTRODUCTION}

O $\mathrm{NE}$ of the engineering challenges of magnetic confinement fusion is handling the high particle and heat fluxes incident on the divertor. Solid plasma facing materials must withstand these difficult conditions with a minimum of erosion, melting, and cracking. Liquid metals as plasma facing materials potentially alleviate all of these concerns, and are therefore being actively investigated for that purpose.

With an eye toward assessing the impacts of different liquid metal PFCs beyond the plasma-material interface (i.e. on the tokamak and ancillary systems as a whole), some additions must be made to codes such as MELCOR for Fusion that are used to perform thermal hydraulic and safety analyses of such systems. MELCOR was originally developed to model the progression of light water reactor accidents, and is therefore fundamentally a multi-phase fluid code. It was subsequently modified to model other fluids, including liquid metals relevant to fusion such as $\mathrm{Li}$ and $\mathrm{PbLi}$, by replacing the original multiphase water properties with those derived from a suitable equation of state; this allows for specification of the full range of multi-phase and saturated properties even where they may not be known, i.e. for the vapor phase.

Lithium is a primary candidate liquid metal PFC, and past interest in lithium as a tritium breeding material has resulted in comprehensive physical property summaries, including development of an equation of state subsequently implemented in both RELAP5 an MELCOR for Fusion. Tin is an interesting

Paul W. Humrickhouse is with Idaho National Laboratory, Idaho Falls, ID 83415 USA, e-mail: paul.humrickhouse@inl.gov. alternative; though it has a higher atomic number $(\mathrm{Z}=50)$, it has a suitably low melting temperature $\left(232{ }^{\circ} \mathrm{C}\right)$, low vapor pressure, and lacks the high chemical reactivity and high tritium solubility of lithium.

The available measured thermophysical properties of liquid tin, including density, specific heat, sound speed, vapor pressure, thermal conductivity, viscosity, surface tension, and hydrogen isotope solubility and diffusivity, are summarized in this work. The thermodynamic property data (density, specific heat, sound speed, and vapor pressure) are then used to develop an equation of state for liquid tin that accurately predicts the density, specific heat, and sound speed of the liquid throughout the temperature range in which they have been measured, while simultaneously closely approximating the vapor pressure up to the normal boiling point. This equation has been implemented in MELCOR along with correlations for the transport properties. The transport properties of tritium are also important for the conduction of safety analyses, and tritium transport models have recently been implemented in MELCOR for Fusion [1]. The available data on the solubility and diffusivity of hydrogen in liquid tin that might be used to conduct such analyses are summarized in Section IV-D.

\section{Thermodynamic Properties}

\section{A. Density}

Many density measurements have been made in liquid tin. These have recently been critically reviewed by Assael [2] for the purpose of establishing a reference correlation, taking into account the methods employed and uncertainty in the data obtained. The recommended correlation, applicable over the temperature range $506-1950 \mathrm{~K}$, is

$$
\rho_{m}-c\left(T-T_{m}\right)
$$

where $T_{m}=505.08 \mathrm{~K}$ is the melt temperature, $\rho_{m}=6979$ $\mathrm{kg} \mathrm{m}^{-3}$ is the density at melt, and $c=0.652 \mathrm{~kg} \mathrm{~m}^{-3} \mathrm{~K}^{-1}$. We use these reference values in fitting our equation of state.

\section{B. Specific Heat and Vapor Pressure}

Specific heat data and vapor pressure data were collected and summarized by Hultgren [3], who provided tabular reference values based on these. The collection was revised and expanded a decade later [4]. Those values have subsequently 
been adopted in other reference texts [5], [6] which additionally provide reference correlations. We use the ones given in [5], viz.

$$
\begin{gathered}
c_{p}\left[\mathrm{~J} \mathrm{~kg}^{-1} \mathrm{~K}^{-1}\right]=182.7+5.177 \mathrm{e}-2 T+1.086 \mathrm{e} 7 T^{-2} \\
P_{\text {sat }}[\mathrm{Pa}]=2.8567 \mathrm{e} 9 T^{\frac{1}{4}} \exp \left(\frac{-35163}{T}\right)
\end{gathered}
$$

\section{Sound Speed}

There seems not to be a universally agreed upon correlation for sound speed as a function of temperature in liquid tin. Several texts summarizing sound speed data in liquid metals [7]-[9] provide multiple correlations from different sources (though not all the same ones) without making any explicit recommendation as to which should be used. We have therefore collected here all the data that could be obtained [10]-[19], which are plotted in Figure 1; where individual data points were reported, these are plotted. Where only a correlation has been reported, this is shown with a line spanning the temperature range in which the data were supposed to be taken. It can be seen that the values reported by Kleppa [10] and Berthou [16] are well below the range of all others; Filippov's data are also lower throughout the lower temperature range and exhibit more scatter than the other data sets. The remainder fall within a much smaller range. Turner's [17] correlation is intermediate among these, and matches well most of the low temperature data near the melting point [11]-[13], [18] and also the higher temperature data that are available [15], [19]. For these reasons we adopt it as a reference. It is given by:

$$
w[\mathrm{~m} / \mathrm{s}]=2605-0.258 T \text {. }
$$

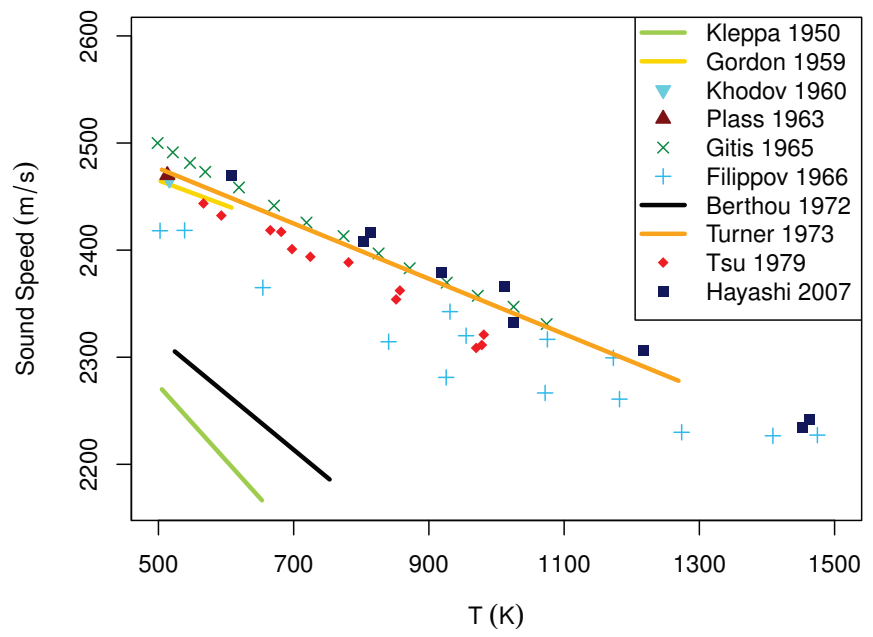

Fig. 1. Sound speed in liquid tin.

\section{EQUATION OF STATE}

\section{A. General Form}

We choose as the general form of our equation of state a Helmholtz potential of the type widely used in the formulation of reference equations of state and discussed extensively in [20]:

$$
\begin{aligned}
& \frac{a}{R_{s} T}=s_{0}+u_{0}\left(\frac{T_{m}}{T}\right)+\ln \left(\frac{\rho}{\rho_{m}}\left(\frac{T_{m}}{T}\right)^{\frac{3}{2}}\right) \\
& \quad+\sum_{i=1}^{N} n_{i}\left(\frac{T_{m}}{T}\right)^{t_{i}}\left(\frac{\rho}{\rho_{m}}\right)^{d_{i}} \exp \left(-\gamma_{i}\left(\frac{\rho}{\rho_{m}}\right)^{p_{i}}\right) .
\end{aligned}
$$

Here $a, \rho$, and $T$ have units of $\mathrm{J} / \mathrm{kg}, \mathrm{kg} / \mathrm{m}^{3}$, and $\mathrm{K}$, respectively, and we alternate the use of density $\rho$ and specific volume $v=1 / \rho$ as convenient throughout. Density and temperature are typically normalized with respect to critical point values; the critical point for tin seems not to be precisely known and is far outside the range of applicability of the present equation (and practical thermal hydraulic analyses more generally) so we use instead the value at the melting point, $T_{m}=505.08$ $\mathrm{K}$ and $\rho_{m}=6979 \mathrm{~kg} / \mathrm{m}^{3}$ [2]. $R_{s}$ is the specific gas constant (70.04 J/kg-K for $\mathrm{Sn}$ ), and the constants $u_{0}$ and $s_{0}$ are so named because they serve only to fix the reference energy and entropy, respectively; they vanish in the expressions for pressure and all second order derivatives.

\section{B. Fitting the EOS}

The advantage of defining an equation of state in terms of the Helmholtz free energy is that all other thermodynamic properties can be simply derived from it. The pressure and (specific) entropy are defined by the derivatives with respect to $v$ and $T$ (respectively), viz.:

$$
\begin{aligned}
& P(v, T)=-\left(\frac{\partial a}{\partial v}\right)_{T} \\
& s(v, T)=-\left(\frac{\partial a}{\partial T}\right)_{v} .
\end{aligned}
$$

In order to fit the equation of state, we make use of the reference correlations for density, specific heat, and sound speed outlined previously. $\rho(T)$ data can be compared to those obtained from the equation of state (EOS) by solving equation 6 for density at the appointed temperature and pressure (e.g. atmospheric); specific heat $\left(c_{P}\right)$ and sound speed $(w)$ are are computed using these densities and the second derivatives of the Helmholtz free energy (functions of $v$ or $\rho$ and T) using the usual thermodynamic manipulations [21], [22]:

$$
\begin{aligned}
w & =\sqrt{\left(\frac{\partial P}{\partial \rho}\right)_{s}} \\
& =v \sqrt{\left(\left(\frac{\partial P}{\partial T}\right)_{v}^{2} /\left(\frac{\partial s}{\partial T}\right)_{v}\right)-\left(\frac{\partial P}{\partial v}\right)_{T}} \\
c_{p} & =T\left(\frac{\partial s}{\partial T}\right)_{P} \\
& =T\left[\left(\frac{\partial s}{\partial T}\right)_{v}-\left(\left(\frac{\partial P}{\partial T}\right)_{v}^{2} /\left(\frac{\partial P}{\partial v}\right)_{T}\right)\right]
\end{aligned}
$$

In addition, we can make use of saturation pressure data in fitting the equation of state, and matching these becomes more 
important for PFC applications where one wishes to evaluate transients where significant vaporization might occur, and where evaporation rates govern the mobilization of activation products. The saturation conditions are obtained from the equation of state based on the fact that the coexisting phases are in thermal, mechanical, and chemical equilibrium, i.e. that they have the same temperature, pressure, and Gibbs free energy. Mathematically, $P_{s a t}, v_{\ell}$, and $v_{v}$ are obtained by solving, for a given $T_{\text {sat }}$,

$$
\begin{gathered}
P_{\text {sat }}=P\left(v_{\ell}, T_{\text {sat }}\right) \\
P_{\text {sat }}=P\left(v_{v}, T_{\text {sat }}\right) \\
P_{\text {sat }}\left(v_{\ell}-v_{v}\right)=a\left(v_{v}, T_{s a t}\right)-a\left(v_{\ell}, T_{\text {sat }}\right) .
\end{gathered}
$$

In order to fit the equation of state, we define an objective function that is the sum of squares of the differences between a set of values obtained from the reference correlations and those calculated from the EOS, and minimize it by adjusting the parameters using the nlm package in $\mathrm{R}$ [23]:

$$
\zeta^{2}=\sum_{1=m}^{M} W_{m}\left(\frac{y_{E O S, m}-y_{\text {ref }, m}}{y_{\text {ref }, m}}\right)^{2}
$$

Here $y$ includes all data types including density, specific heat, sound speed, and vapor pressure. Relative differences are used (i.e. each difference is normalized to the measured value) to account for the different magnitudes of the properties. An additional factor $W$ allows for weighting of different data sets based on their uncertainty, but because of the above-mentioned normalization and the fact that we compare to reference values instead of actual data points, there is no need for this in the present analysis.

Obtaining a good solution from the optimization is nontrivial because of the necessary inclusion of root finding and equation solving routines within the objective function. The density, specific heat, and sound speed data described previously rarely report a pressure explicitly; they are given as functions of temperature only. We assume the pressure is atmospheric; then, evaluating the density from the EOS involves finding the three densities that give a pressure equal to $101325 \mathrm{~Pa}$ at the specified temperature (finding the three roots of equation 6), and selecting the highest of these, the one that corresponds to the liquid density. The same root finding is required to find the density needed for calculating $c_{p}(v, T)$ and $w(v, T)$. This problem is particularly acute for the vapor pressure; in this case, evaluating $P_{\text {sat }}$ from the EOS for a given $T_{\text {sat }}$ requires solving equations $10-12$ for $P_{\text {sat }}, v_{\ell}$, and $v_{v}$. Large changes in the fit parameters during optimization tend to prevent this solution from converging, and therefore good initial values of the parameter set are required.

For fluids on which large amounts of data are available, e.g. in both liquid and vapor phases and over a very large range of temperatures, development of accurate reference equations of state based on forms such as equation 5 typically requires a large number of terms- from $\sim 20$ to as many as 60 or 70 . These are selected from larger banks of hundreds of terms possessing different exponents on temperature and density, using algorithms described in [20]. Given the comparatively narrow temperature range in which we need to match liquid tin data, only a few such terms are needed, and we take a three term equation of state for PbLi previously implemented in MELCOR as a starting point. The exponents on temperature and density are themselves adjusted during optimization, and trial terms are added and also adjusted until an accurate match to all the reference correlation is achieved. Such a fit is achieved for liquid tin with six terms, two of which are density-independent and one of which is an exponential term. The fit parameters are summarized in Table I, and the close agreement with reference values shown in Figures 2-5. We set $u_{0}=71.74$ and $s_{0}=9.928$ such that the internal energy and entropy are zero at the melting point, i.e. $u\left(\rho_{m}, T_{m}\right)=0$ and $s\left(\rho_{m}, T_{m}\right)=0$.

TABLE I

SN FIT PARAMETERS FOR EQUATION $5(\mathrm{~N}=6)$.

\begin{tabular}{|c|c|c|c|c|c|}
\hline$i$ & $n_{i}$ & $t_{i}$ & $d_{i}$ & $\gamma_{i}$ & $p_{i}$ \\
\hline \hline 1 & -12.17 & 0.260 & 0 & 0 & 0 \\
\hline 2 & -4.165 & -0.260 & 0 & 0 & 0 \\
\hline 3 & -93.35 & 1.005 & 0.832 & 0 & 0 \\
\hline 4 & -0.329 & 2.053 & 1.502 & 0 & 0 \\
\hline 5 & 18.47 & 1.047 & 3.403 & 0 & 0 \\
\hline 6 & 33.18 & 0.410 & 2.715 & 1.212 & 1.043 \\
\hline
\end{tabular}

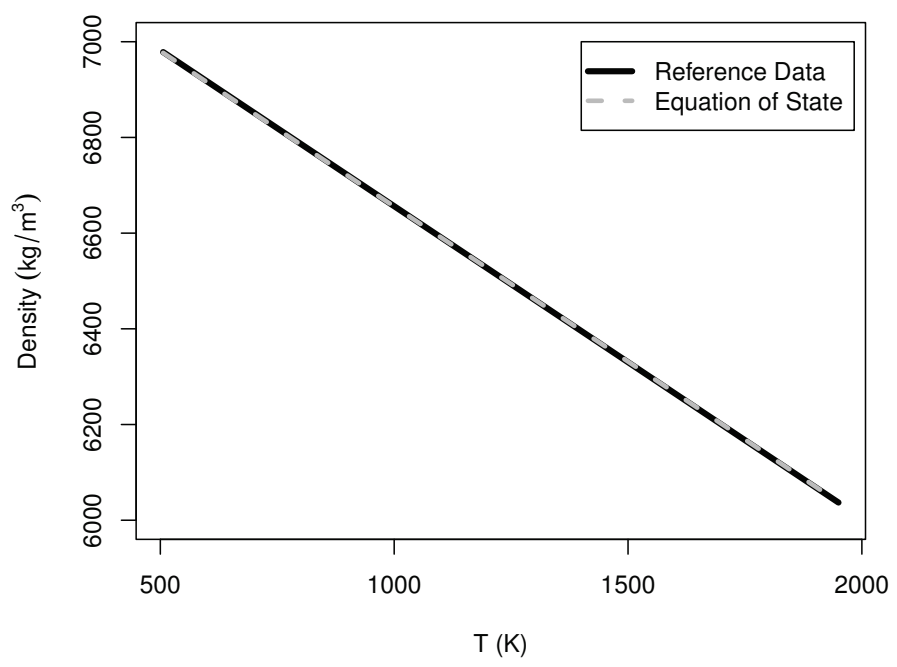

Fig. 2. Sn density reference data [2] compared with the new equation of state.

\section{TRAnsport And OTHER PROPERTIES}

Other liquid metal transport properties (i.e. thermal conductivity, viscosity, and surface tension) are implemented in MELCOR directly as correlations. We therefore need only to select the most suitable of these.

\section{A. Thermal Conductivity}

A comparison of 15 thermal conductivity data sets has been presented recently by Savchenko et al. [24], who performed one set of those experiments. All but two of these fall between $30-35 \mathrm{~W} / \mathrm{m}-\mathrm{K}$ at $600 \mathrm{~K}$, and most of these are closer to $\sim 32$ $\mathrm{W} / \mathrm{m}-\mathrm{K}$; however the trend with temperature appears rather 


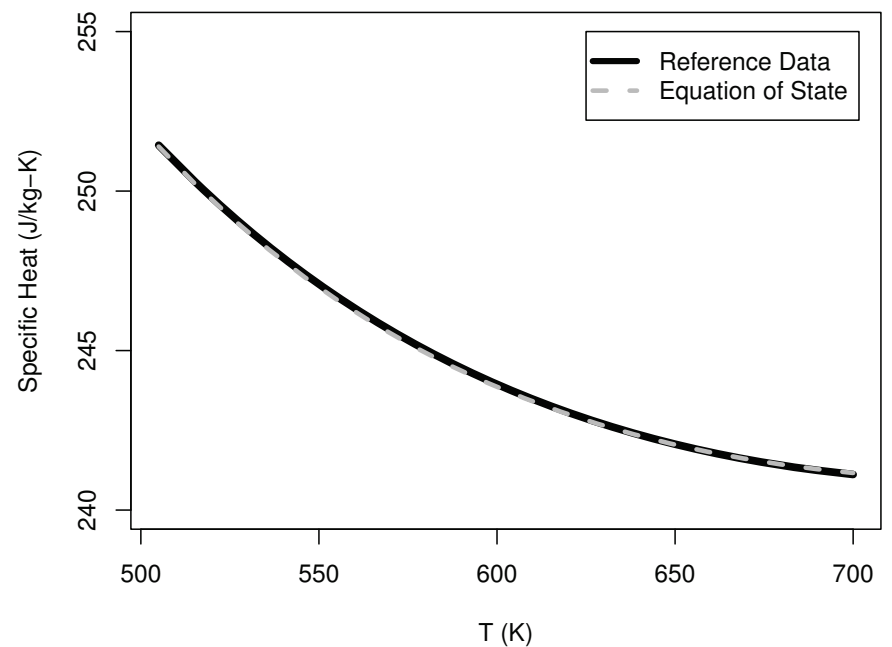

Fig. 3. Sn specific heat reference data [5] compared with the new equation of state.

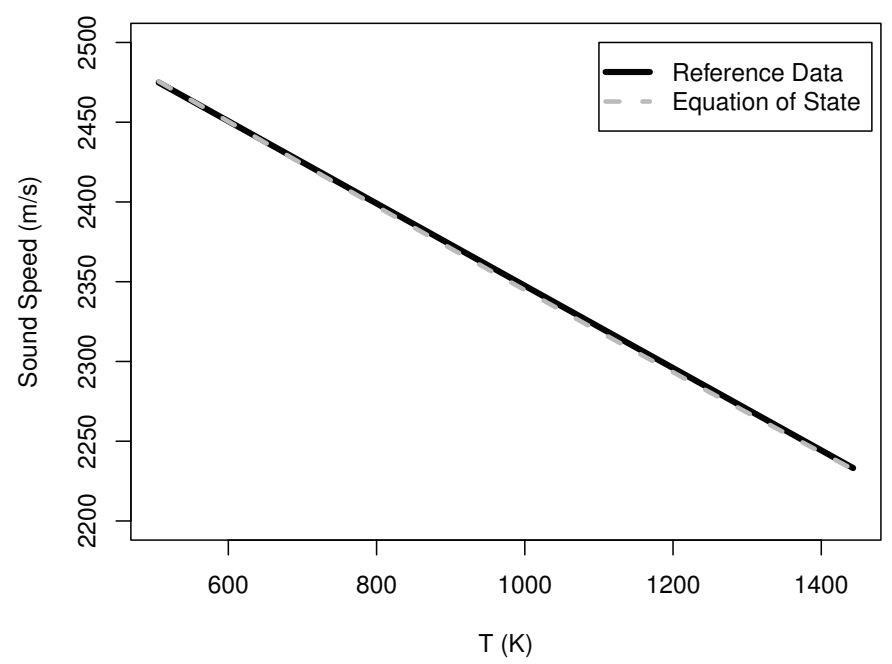

Fig. 4. Sn sound speed reference data [17] compared with the new equation of state.

uncertain, and few of these data extend beyond $1000 \mathrm{~K}$. At $1200 \mathrm{~K}$ the bounds are given on the low end by [25], who indicate no change from $\sim 32 \mathrm{~W} / \mathrm{m}-\mathrm{K}$ over the range $600-1200$ $\mathrm{K}$ (with $8 \%$ uncertainty), and on the high end by Savchenko, who report the correlation:

$$
\lambda[\mathrm{W} / \mathrm{m} \cdot \mathrm{K}]=13.90+0.02868 T
$$

and $\lambda=48.31 \mathrm{~W} / \mathrm{m}-\mathrm{K}$ at $1200 \mathrm{~K}$ (with $3.5 \%$ uncertainty). In this temperature range there is almost no additional data that might recommend higher versus lower values, and so presently in MELCOR we are working with "design basis" and "beyond design basis" versions, the latter featuring various other conservatisms in addition to assuming the lower bound of thermal conductivity. The influence of this will be assessed as the code is exercised in design studies.

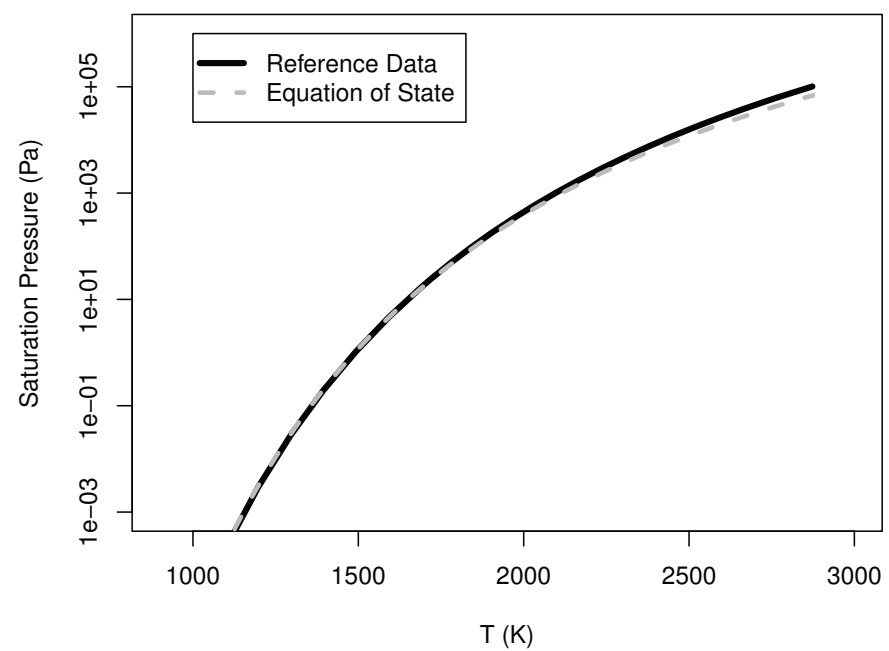

Fig. 5. Sn vapor pressure reference data [5] compared with the new equation of state.

\section{B. Surface Tension}

Surface tension data have recently been summarized by Novakovic et al. [26], who in the course of measuring this property in Au-Sn alloys also collected and compared 15 data sets on pure tin. These center around $0.56 \mathrm{~N} / \mathrm{m}$ near the melting point and are spread throughout the range 0.54-0.58 $\mathrm{N} / \mathrm{m}$ there, and decrease linearly with temperature to a mean of around $0.54 \mathrm{~N} / \mathrm{m}$ with a similar spread at $500{ }^{\circ} \mathrm{C}$. The correlation of Kasama [27] was selected for implementation in MELCOR as it falls in the center of the range of data (both in magnitude and slope). It is given by:

$$
\gamma[\mathrm{N} / \mathrm{m}]=0.606-9.1 \mathrm{e}-5 T \text {. }
$$

\section{Viscosity}

Viscosity data have been reviewed alongside density data by Assael [2], applying the same level of rigor in evaluating the data based on the methods employed and uncertainties reported. The reference correlation given is

$$
\eta[\mathrm{Pa} \cdot \mathrm{s}]=3.908 \mathrm{e}-4 \exp \left(\frac{790.7}{T}\right),
$$

applicable over the temperature range 506-1280 K. This correlation has been implemented in MELCOR.

\section{Tritium Solubility and Diffusivity}

There are few measured data on the solubility of hydrogen or its isotopes in liquid tin. The earliest are by Iwasé [28], which are the values reported in [29] and subsequently adopted in fusion texts, e.g. [30], [31]. These data were regarded as erroneously high by Bever and Floe [32] who measured much lower values. They also found inadequate the measurements of Bircumshaw [33], in which equilibrium had not been reached. These data are all shown in Figure 6. In all cases Sieverts' constant can be described by the Arrhenius law

$$
K_{S}=K_{0} \exp \left(\frac{-E_{a}}{R T}\right)
$$


TABLE II

ARRHENIUS PARAMETERS FOR SIEVERTS' CONSTANT.

\begin{tabular}{|c|c|c|c|}
\hline Reference & {$[28]$} & {$[33]$} & {$[32]$} \\
\hline \hline$K_{0}\left(\mathrm{~mol} \mathrm{~m}^{-3} \mathrm{P}^{-1 / 2}\right)$ & 0.0769 & 0.125 & 20.64 \\
\hline$E_{a}\left[\mathrm{~J} \mathrm{~mol}{ }^{-1} K^{-1}\right]$ & 8,989 & 34,730 & 114,846 \\
\hline
\end{tabular}

and the parameters for each data set are given in Table II.

We could identify only one attempt to measure diffusivity of hydrogen in liquid tin [34], but only a range of values was given in that work. The data were thought unreliable in part because $D$ decreased with increasing temperature; the authors rightly found that trend suspect. The method relied on knowledge of the solubility, for which they had used a correlation based on the data of Bever and Floe. Communications between the authors revealed that the solubility data probably had a much larger uncertainty than previously realized; as a result, a precise estimate of the diffusion coefficient could not be made by Sacris.

More recently an as-yet unpublished ab initio estimate of the diffusion coefficient has been made by Liu et al. [35] using density functional theory. Care was taken to show that the method reasonably reproduced experimentally determined diffusion coefficients in lithium. The estimated correlation for $D_{2}$ in liquid tin was:

$$
D\left[\mathrm{~m}^{2} / \mathrm{s}\right]=2.33 \mathrm{e}-7 \exp \left(\frac{-11980}{R T}\right) .
$$

This is rather lower than the approximate range of values given by Sacris, as shown in Figure 7.

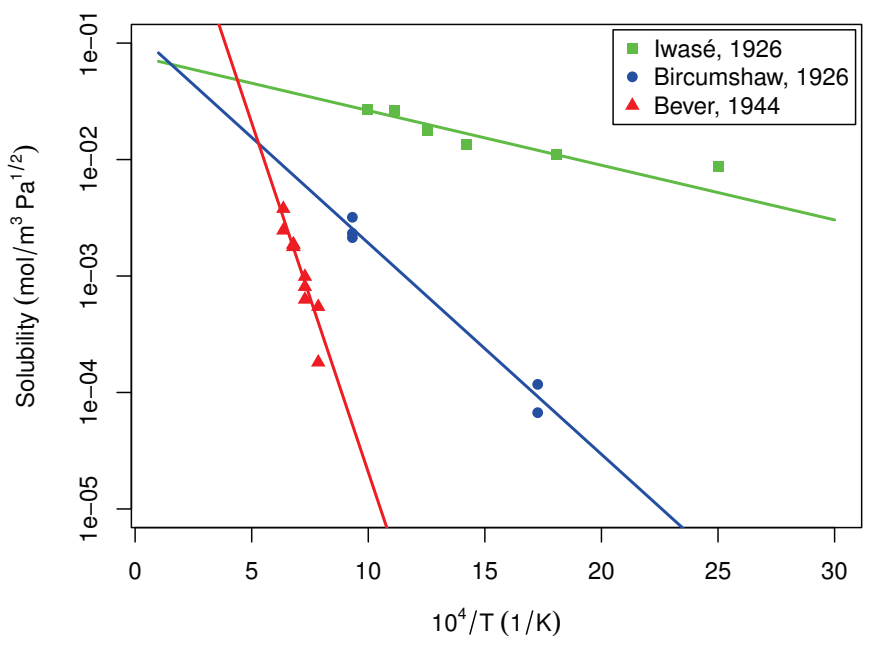

Fig. 6. Solubility of $\mathrm{H}_{2}$ in liquid tin.

\section{CONCLUSiOns}

A wide variety of thermophysical property data for liquid tin have been summarized herein. Density and viscosity data have recently been critically reviewed for the purpose of establishing reference correlations, and we adopt these for use in MELCOR, either via direct implementation or use in developing an equation of state. Specific heat and vapor pressure data have given rise to standard reference values and

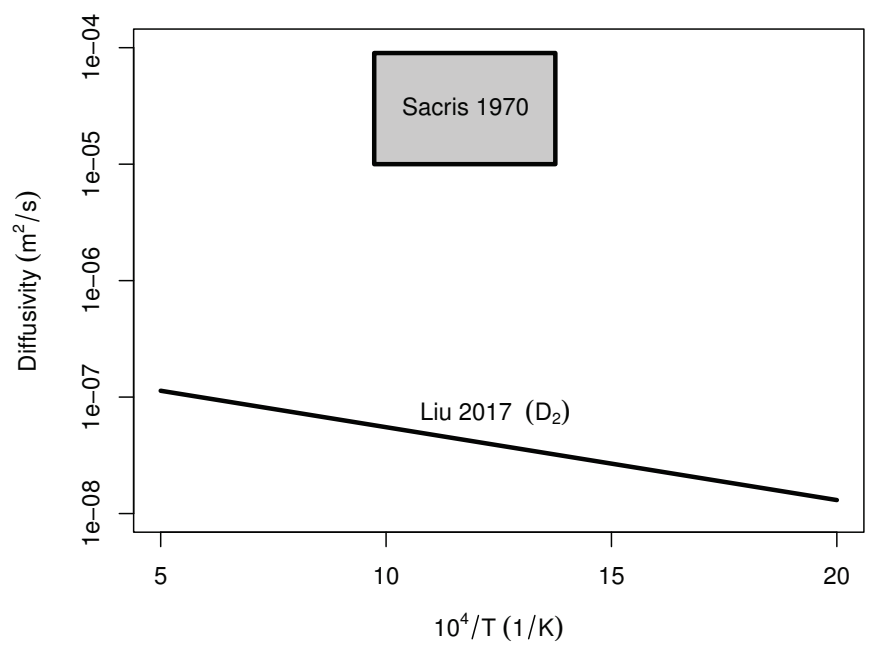

Fig. 7. Diffusivity of $\mathrm{H}_{2}$ in liquid tin.

correlations at earlier times, and we adopt these in developing an equation of state as well.

Sound speed, surface tension, and thermal conductivity have all been measured numerous times in the past, and papers comparing many data sets for surface tension and thermal conductivity have been published in recent years. Sound speed data appear in many different sources, but these have been compiled and compared herein. We select reference correlations for sound speed and surface tension that fall within the center of the range of measured values, discounting outliers in a few cases. The thermal conductivity data do not all show a coherent trend, and the implications of using bounding values will be explored in upcoming MELCOR analyses.

The density, specific heat, sound speed, and vapor pressure reference correlations are used to fit an equation of state. The six-term Helmholtz potential developed here is shown to reproduce all of these properties accurately over the range of temperatures in which the correlations are valid. This equation of state has been used to generate a liquid tin fluid property file which is now available in MELCOR for Fusion.

What few data were available for hydrogen solubility and diffusivity have also been summarized. Perhaps not surprisingly given recent experience with other liquid metals such as lead-lithium eutectic, the three solubility data sets span several orders of magnitude. One attempt to measure diffusivity did not produce a correlation, in part because the analysis was reliant upon the uncertain solubility data. There has been one recent theoretical estimate of deuterium diffusivity in liquid tin, and this will have to be relied upon in future analyses with the latest version of MELCOR for Fusion, which incorporates tritium transport models. The implications of the uncertainty in solubility will be explored in these analyses as well.

\section{ACKNOWLEDGMENT}

This material is based upon work supported by the U.S. Department of Energy, Office of Science, Office of Fusion Energy Sciences, under contract number DE-AC07-05ID14517. 


\section{REFERENCES}

[1] B. J. Merrill, P. W. Humrickhouse, and M. S. Shimada, "Recent development and application of a new safety analysis code for fusion reactors," Fusion Engineering and Design, vol. 109-111, Part A, pp. 970-974, November 2016.

[2] M. J. Assael, A. E. Kalyva, K. D. Antoniadis, R. M. Banish, I. Egry, J. Wu, E. Kaschnitz, and W. A. Wakeham, "Reference data for the density and viscosity of liquid copper and liquid tin," Journal of Physical and Chemical Reference Data, vol. 39, no. 3, p. 033105, 2010. [Online]. Available: http://dx.doi.org/10.1063/1.3467496

[3] R. Hultgren, R. L. Orr, P. D. Anderson, and K. K. Kelley, Selected Values of Thermodynamic Properties of Metals and Alloys. New York: John Wiley and Sons, 1963.

[4] R. Hultgren, P. D. Desai, D. T. Hawkins, M. Gleiser, K. K. Kelley, and D. D. Wagman, Selected Values of the Thermodynamic Properties of the Elements. Metals Park, Ohio: American Society for Metals, 1973.

[5] O. Knacke, O. Kubaschewski, and K. Hesselmann, Eds., Thermochemical Properties of Inorganic Substances. Berlin: Springer-Verlag, 1991

[6] M. Binnewies and E. Milke, Thermochemical Data of Elements and Compounds. Weinheim, Germany: Wiley-VCH, 2002.

[7] R. T. Beyer and E. M. Ring, "Sound propagation in liquid metals," in Liquid Metals: Chemistry and Physics, S. Z. Beer, Ed. New York: Marcel Dekker, 1972, pp. 411-430.

[8] T. Iida and R. I. L. Guthrie, The physical properties of liquid metals. Oxford: Clarendon Press, 1988.

[9] Y. Kawai and Y. Shiraishi, Handbook of Physico-chemical Properties at High Temperatures. Iron and Steel Institute of Japan, 1988.

[10] O. J. Kleppa, "Ultrasonic velocities of sound in some metallic liquids. adiabatic and isothermal compressibilities of liquid metals at their melting points," The Journal of Chemical Physics, vol. 18, no. 10 , pp. 1331-1336, 1950. [Online]. Available: http://dx.doi.org/10.1063/1. 1747472

[11] R. Gordon, "Propagation of sound in liquid metals: The velocity in lead and tin," Acta Metallurgica, vol. 7, no. 1, pp. 1 - 7, 1959. [Online]. Available: http://www.sciencedirect.com/science/article/ pii/0001616059901622

[12] Z. L. Khodov, Physics of Metals and Metalworking (in Russian), vol. 10, no. 5, pp. 772-779, 1960.

[13] K. G. Plass, "Ultraschallmessungen in metallen im geschmolzenen zustand und beim erstarren," Acustica, vol. 13, pp. 240-244, 1963.

[14] M. B. Gitis and I. G. Mikhailov, "Velocity of sound and compressibility of certain liquid metals," Soviet Physics - Acoustics, vol. 11, no. 4, pp. 372-375, 1966.

[15] N. B. K. S. I. Filippov and L. A. Pronin, "Velocities of ultrasonic waves, compressibility of liquid metals and their relation to various physical properties (in russian)," Izv. Vyssh. Uchebn., Zaved. Chern. Metall., vol. 9, no. 3, pp. 8-14, 1966.

[16] P.-E. Berthou and R. Tougas, "The compressibilities of liquid sn-tl, in-bi, sn-ln, bi-sb, and bi-cd-tl alloys," Metallurgical Transactions, vol. 3, no. 1, pp. 51-54, 1972. [Online]. Available: http://dx.doi.org/10. 1007/BF02680584

[17] R. Turner, E. D. Crozier, and J. F. Cochran, "Compressibility and partial structure factors in the zero-wavevector limit of liquid copper-tin alloys," Journal of Physics C: Solid State Physics, vol. 6, no. 23, p. 3359, 1973. [Online]. Available: http://stacks.iop.org/0022-3719/6/i=23/a=011

[18] K. T. Y. Tsu, Y. Shiraishi and S. Watanabe, "The velocity of ultrasonic wave in liquid tin, lead and zinc (in japanese)," J. Jpn. Inst. Met. Mater. vol. 43, no. 5, pp. 439-446, 1979.

[19] M. Hayashi, H. Yamada, N. Nabeshima, and K. Nagata, "Temperature dependence of the velocity of sound in liquid metals of group xiv," International Journal of Thermophysics, vol. 28, no. 1, pp. 83-96, 2007. [Online]. Available: http://dx.doi.org/10.1007/s10765-007-0151-9

[20] R. Span, Multiparameter Equations of State. Berlin: Springer, 2000.

[21] H. B. Callen, Thermodynamics and an Introduction to Thermostatistics, 2nd ed. New York: John Wiley I\& Sons, 1985.

[22] J. J. de Pablo and J. D. Schieber, Molecular Engineering Thermodynamics. Cambridge: Cambridge University Press, 2014.

[23] R Core Team, R: A Language and Environment for Statistical Computing, R Foundation for Statistical Computing, Vienna, Austria, 2015. [Online]. Available: https://www.R-project.org

[24] I. V. Savchenko, S. V. Stankus, and A. S. Agadjanov, "Measurement of liquid tin heat transfer coefficients within the temperature range of 506-1170 k," High Temperature, vol. 49, no. 4, p. 506, 2011. [Online]. Available: http://dx.doi.org/10.1134/S0018151X11040171

[25] R. P. Yurchak and L. P. Fillipov, Teplofiz. Vys. Temp., vol. 3, no. 2, p. 323, 1965.
[26] R. Novakovic, E. Ricci, F. Gnecco, D. Giuranno, and G. Borzone, "Surface and transport properties of au-sn liquid alloys," Surface Science, vol. 599, no. 1, pp. 230 - 247, 2005. [Online]. Available: http://www.sciencedirect.com/science/article/pii/S0039602805011362

[27] A. Kasama, T. Iida, and Z. ichiro Morita, "Temperature dependence of surface tension of liquid pure metals," Journal of the Japan Institute of Metals, vol. 40, no. 10, pp. 1030-1038, 1976.

[28] K. Iwasé, "Occlusion of gases by metals and alloys in liquid and solid states," The Science Reports of the Tōhoku University, First Series, vol. 15 , p. 531, 1926.

[29] W. M. Mueller, J. P. Blackledge, and G. G. Libowitz, Metal Hydrides. New York: Academic Press, 1968.

[30] V. Maroni and E. V. Deventer, "Materials considerations in tritium handling systems," Journal of Nuclear Materials, vol. 85, pp. 257 269, 1979. [Online]. Available: http://www.sciencedirect.com/science/ article/pii/0022311579905002

[31] E. Teller, Ed., Fusion, Volume 1: Magnetic Confinement, Part B. New York: Academic Press, 1981.

[32] M. B. Bever and C. F. Floe, "Solubility of hydrogen in molten coppertin alloys," Transactions of the American Institute of Mining and Metallurgical Engineers, vol. 156, pp. 149-159, 1944.

[33] L. L. Bircumshaw, "The solubility of hydrogen in tin and aluminium at high temperatures," The London, Edinburgh, and Dublin Philosophical Magazine and Journal of Science, vol. 1, no. 2, pp. 510-522, 1926. [Online]. Available: http://dx.doi.org/10.1080/14786442608633651

[34] E. M. Sacris and N. A. D. Parlee, "The diffusion of hydrogen in liquid ni, cu, ag, and sn," Metallurgical Transactions, vol. 1, no. 12, pp. 3377 3382, 1970. [Online]. Available: http://dx.doi.org/10.1007/BF03037867

[35] X. Liu, D. Zheng, X. Ren, L. He, and M. Chen, "First-principles molecular dynamics study of deuterium diffusion in liquid tin," 2017. [Online]. Available: https://arxiv.org/abs/1701.03879

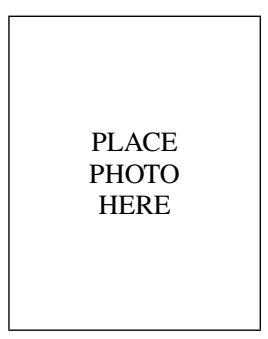

Biography. 